\title{
Pemanfaatan Web Sebagai Sistem Informasi PPDB pada SLBN Koba Bangka Tengah
}

\author{
Lili Indah Sari \\ ISB Atma Luhur \\ Pangkalpinang, Indonesia \\ lilie@atmaluhur.ac.id \\ Ellya Helmud \\ ISB Atma Luhur \\ Pangkalpinang, Indonesia \\ ellyahelmud@atmaluhur.ac.id
}

\author{
Wishnu Aribowo Probonegoro \\ ISB Atma Luhur \\ Pangkalpinang, Indonesia \\ Wishnuap77@atmaluhur.ac.id \\ Sri Lestari \\ ISB Atma Luhur \\ Pangkalpinang, Indonesia \\ Slestari93@yahoo.com
}

\begin{abstract}
Pendidikan merupakan kebutuhan dasar setiap manusia. Anak-anak yang memiliki perbedaan kemampuan (difabel) disediakan fasilitas pendidikan khusus di sesuaikan dengan derajat danjenis difabelnya yang disebut dengan Sekolah Luar Biasa (SLB).Sekolah Luar Biasa adalah sebuah lembaga pendidikan formal yang melayani pendidikan bagi anak-anak berkebutuhan khusus. Sekolah Luara Biasa Negeri Koba merupakan salah satu sekolah berkebutuhan khusus yang ada di kabupaten Bangka Tengah yaitu di daerah Koba. SLBN Koba merupakan satu satunya SLB Negeri yang ada di Kabupaten, hal ini akan berpengaruh pada penerimaan peserta didik baru (PPDB) yang ada di SLBN, karena letaknya yang jauh dan terpencil. Pada saat PPDB orang tua atau wali murid harus datang dan daftar langsung ke sekolah tersebut. Hal ini akan merepotkan karena harus bolak balik kesekolah, ditambah sistem PPDB yang ada di SLBN Koba masih dilakukan secara manual. Oleh karena itu, Dengan adanya masalah yang ada di atas maka penulis ingin membuat suatu Sistem Penerimaan Peserta Didik Baru bertujuan untuk mempermudah orang tua siswa dalam pendaftaran PPDB dan sekolah SLBN dalam pengolaan data siswa baru yang diperlukan. Dalam hal ini penulis menggunakan model waterfall dan tool yang akan digunakan untuk merancang sistem ini menggunakan Unified Modelling Languange (UML).
\end{abstract}

Kata kunci: PPDB(Penerimaan Peserta Didik Baru), SLBN Koba,Sistem, UML,web.

I. Pendahuluan

Setiap Warga Negara Indonesia berhak mendapatkan pendidikan, karena hal ini diatur didalan undan-undang dasar 1945. Pedidikan merupakan kebutuhan dasar setiap manusia untuk menjamin keberlangsungan hidupnya agar lebih bermanfaat, termasuk mereka yang memiliki perbedaan kemampuan (difabel). Anak-anak yang memiliki perbedaan kemampuan (difabel) disediakan fasilitas pendidikan khusus di sesuaikan dengan derajat dan jenis difabelnya yang disebut dengan Sekolah Luar Biasa (SLB)

Sekolah Luar Biasa adalah sebuah lembaga pendidikan formal yang melayani pendidikan bagi anak-anak berkebutuhan khusus. Sekolah Luara Biasa Negeri Koba merupakan salah satu sekolah berkebutuhan khusus yang ada di kabupaten Bangka Tengah yaitu di daerah Koba. SLBN Koba merupakan satu satunya SLB Negeri yang ada di Kabupaten, hal ini akan berpengaruh pada penerimaan peserta didik baru (PPDB) yang ada di SLBN, karena letaknya yang jauh dan terpencil. Pada saat PPDB orang tua atau wali murid harus datang dan daftar langsung ke sekolah tersebut. Hal ini akan merepotkan karena harus bolak balik ke sekolah, ditambah sistem PPDB yang ada di SLBN Koba masih dilakukan secara manual.Saat ini peranan teknologi Informasi sudah berkembang sangat pesat, adanya kemajuan di dalam perkembangan teknologi informasi pasti membantu dan mempermudah manusia dalam berbagai hal, salah satunya yaitu dengan adanya web. Web akan membantu pihak sekolah dan masyrakat yang akan mendaftarkan anak nya kesekolah khusus di SLBN Koba ini. Dari sisi masyrakat pemanfaat web ini akan lebih menghemat waktu dan biaya pada proses PPDB ini, dari sisi sekolah bisa lebih efektif dan efisien karena sekolah masih menggunkan data secara manual. Dengan adanya pemanfaatan web dan teknologi Informasi dalam hal PPDB ini bisa membantu sekolah. Hal ini yang mendasari penulis membuat penellitian ini.

Berdasarkan latar belakang diatas, maka dapat dirumuskan beberapa masalah yang ada yaitu, Proses PPDB masih dilakukan secara manual sehingga calon siswa merasa kesulitan untuk mendapatkan informasi pendaftaran dan harus bolak balik ke sekolah, proses PPDB dikatakan lambat karena datanya belum terintegrasi dengan baik, bahkan datanya masih berupa arsip, pemanfaatan Web agar bisa di gunakan oleh masyarakat dan sekolah pada PPDB (Penerimaan Peserta Didik Baru) di SLBN Koba, sehingga bisa efisien dan efektif. Supaya sistem ini tidak terlalu luas, maka penulis membatasi sistem yang akan di buat yaitu Sistem yang dibangun hanya tentangPPDB (Penerimaan Peserat Didik Baru ) di Sekolah Luar Biasa Negeri Koba, dalam hal ini hanya PPDB tingkat SD (Sekolah Dasar), yang bisa mengakses sistem PPDB di SLBN Koba yaitu Orangtua Murid / Wali Murid yang sudah daftar dan Pihak Sekolah, sistem ini nantinya dikelola oleh bagian TU sekolah dan di monitoring oleh Kepala Sekolah SLBN Kob, tool dan Model yang akan digunakan pada PPDB berbasis web di SLBN Koba, Sistem ini tidak membahas pembayaran pendaftaran secara online dan akademik. Sistem yang di buat bertujuan Memberi kemudahan bagi orang tua calon siswa untuk mendaftarkan anak mereka secara online ke Sekolah Luar Biasa Negeri Koba tanpa harus datang langsung ke sekolah dan mendapatkan informasi tentang pendaftaran, membuat suatu sistem informasi berbasis web yang dapat memudahkan proses 
administrasi pendaftaran sehingga memberi kemudahan bagi panitia PPDB di SLBN Kob. Dengan adanya sistem informasi berbasis web yang dapat mengatasi pengolahan data calon siswa agar data dapat lebih terintegrasi dan terkelola dengan baik[1]

\section{Metodologi Penelitian}

\section{A. Model Waterfall}

Model SDLC air terjun (waterfall) sering juga disebut model sekuensial linier (sequential linear) atau alur hidup (classic life cycle). Model air terjun menyediakan pendekatan alur hidup perangkat lunak secara sekuensial atau terurut dimulai dari analisis, desain, pengkodean, dan pengujian [2]

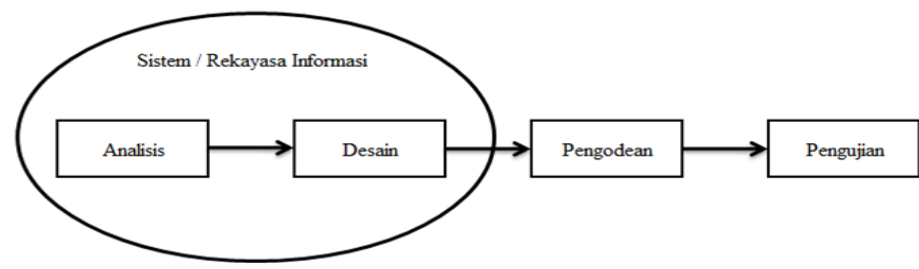

Gambar 1 Model Waterfall

1. Analisa Sistem, Tahap analisa sistem di lakukan untuk mengidentifikasi permasalahan-permasalahan yang terjadi.Proses pengumpulan kebutuhan secara lengkap kemudian dianalisis dan didefinisikan kebutuhan yang seperti apa dan harus dipenuhi serta diinginkan oleh user. Dimana sistem informasi merupakan suatu sistem didalam suatu organisasi yang mempertemukan kebutuhan pengolahan transaksi harian yang mendukung fungsi organisasi yang bersifat manajeral dengan kegiatan strategi dari suatu organisasi untuk dapat menyediakan laporan-laporan yang diperlukan oleh pihak luar tertentu[3]

2. Peracangan Sistem, Setelah analisa sistemtelah dilakukan tahap selanjutnya adalah perancangan sistem yang merupakan tahap menerjemahkan kebutuhan ke dalam sebuah perangkat lunak, pada peracangan sistem ini peneliti menggunakan UML (Unified Model languange).

3. Implementasi, Pembuatan program atau hasil rancangan ke dalam bahasa pemograman tertentu.

4. Pengujian, Melakukan pengujian sistem dengan cara agar sistem valid dan dapat digunakan dengan baik. Pengujian dilakukan agar meminimalisir kesalahan (error) dan memastikan keluaran yang dihasilkan sesuai dengan yang diinginkan

\section{B. Model Penelitian}

Penulis menggunakan metode berorintasi objek yaitu Metode OOAD (Object Oriented Analysis Design). Karena OOAD ini terbagi menjadi 2 tahapan yaitu[4]

1. Object Oriented Analysis, Pada tahap ini adanya proses pengindetifikasian terhadap kebutuhan-kebutuhan, tujuan dari aplikasi atau sistem yang nantinya akan di buat dalam hal ini pada proses PPDB di SLBN Koba.

2. Object Oriented Design, Perancangan terhadap proses-proses yang akan terjadi didalam sistem meliputi perancangan aplikasi pada tahap ini, penulis menggunakan tools Unifed Modelling Language (UML). Tools UML yang dipake penulis meliputi activity diagram, usecase diagram.

Sedangkan untuk perancangan database (basis data) menggunakan Model Entity Relationship Diagram (ERD), dan LRS (Logical Record Structure)

\section{C. .Penelitian Terkait}

"Perancangan Sistem Informasi Penerimaan Siswa baru Berbasis Web.“ dalam penelitian ini menjelaskan bahwa Pendaftaran Calon Siswa baru yang mendaftar di SMP Plus Babussalam, khususnya untuk masuk ke pesantren, mayoritas berasal dari luar kota. Proses penerimaan siswa baru (PSB) di sekolah ini yang masih menggunakan sistem konvensional, sehingga calon siswa terkadang kesulitan mendapatkan informasi untuk melakukan proses pendaftaran, sehingga orang tua atau wali murid harus bolak balik untuk dapat mendaftarkan anaknya di sekolah ini. Proses administrasi juga cenderung lambat, karena data belum terintegrasi dan terkelola dengan baik. Proses ini juga masih menggunakan arsip dalam bentuk fisik. Oleh karena itu di buatlah perancangan dan pembangunan aplikasi Sistem Informasi Penerimaan Siswa Baru Berbasis Web sehingga memudahkan orang tua atau wali murid yang akan memasukan anaknya ke sekolah SMP Plus Babussalam [5]

"Pembangunan Sistem Informasi Penerimaan Siswa Baru di Sekolah Menengah Kejuruan Al-Irsyad Tegal". Dalam penelitian ini menjelaskan bahwa pada umumnya proses penerimaan siswa baru dilakukan melalui tahapan pendaftaran, tes seleksi dan pengumuman penerimaan siswa. Namun pada penerapannya SMK Al-Irsyad masih menggunakan Microsoft Office Excel sehingga kurang efisien dan dibutuhkan sebuah sistem informasi berbasis web yang nantinya dapat membantu proses pendataan penerimaan siswa baru dan untuk meningkatkan keamanan penyimpanan data, otomatisasi perhitungan nilai test serta kemudahan pemberian informasi penerimaan siswa baru[6]

\section{A. Activity Diagram}

III. Hasil dan Pembahasan

Activity diagram digunakan untuk menggambarkan proses bisnis dan urutan aktifitas dalam sebuah proses yang akan dibuat.

Berikut ini adalah gambar activity diagram yang ada di SLBN Koba 
1. Activity Diagram Proses Pedaftaran Calon Siswa Baru ; Pada proses pendaftaran ini orang tua atau wali dari calon siswa yang ingin mendaftarkan anaknya keSLBN Koba bias dating langsung ke sekolah melalui TU sekolah. Pihak TU akan memberikan formulir dan persyaratan lainnya yang harus diisi dan dilengkapi oleh orang tua atau wali dari calon siswa.Formulir yang sudah diisi dikembalikan kembali ke bagian TU, nanti bagian TU akan memeriksa berkas tersebut sudah lengkap atau belum. Hal ini bias dilihat pada Gambar 2 Activity Diagram Proses Pedaftaran Calon Siswa Baru

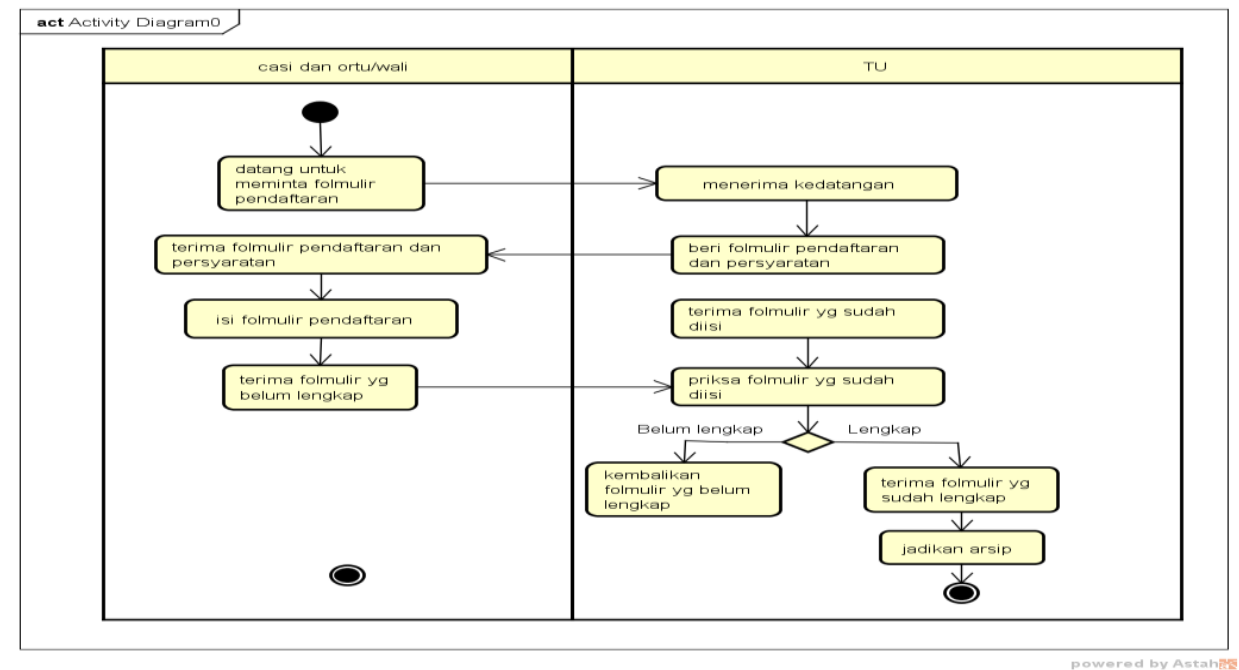

Gambar 2 Activity Diagram Proses Pedaftaran Calon Siswa Baru

2. Activity Diagram Laporan Penerimaan Peserta Didik Baru; Pihak TU membuat laporan penerimaan siswa baru, kemudian menyerahkan laaporan tersebut kepada Kepala Sekolah untuk ditanda tangani, setelah itu nanti pihak TU akan memberikan laporan ke Dinas Pendidikan . Proses ini bisa dilihat pada Gambar 3

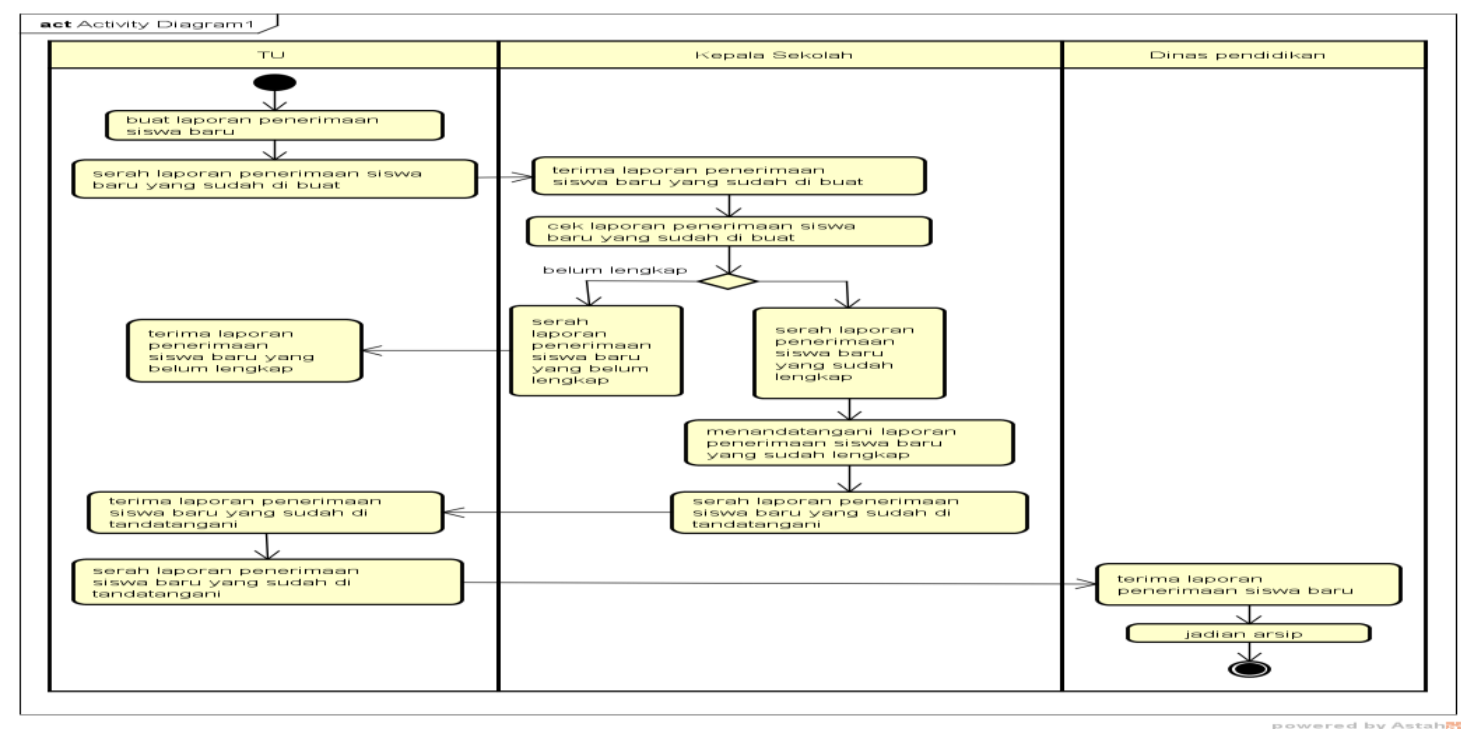

Gambar 3 Activity Diagram Laporan Penerimaan Peserta Didik Baru

3. Activity Diagram Registrasi Peserta Didik

Pada proses ini Orang tua/wali calon siswa menyerahkan dokumen persyaratan, dokumen nanti akan diperiksa kelengkapannya. Jika belum lengkap nanti akan dikembalikan kepada orang tua/wali calon siswa, tetapi jika sudah lengkap pihak TU akan memberikan Formulir Registrasi untuk diisi kembali oleh orangtua/wali calon siswa. Proses ini bias dilihat pada gambar 4 dibawah ini . 


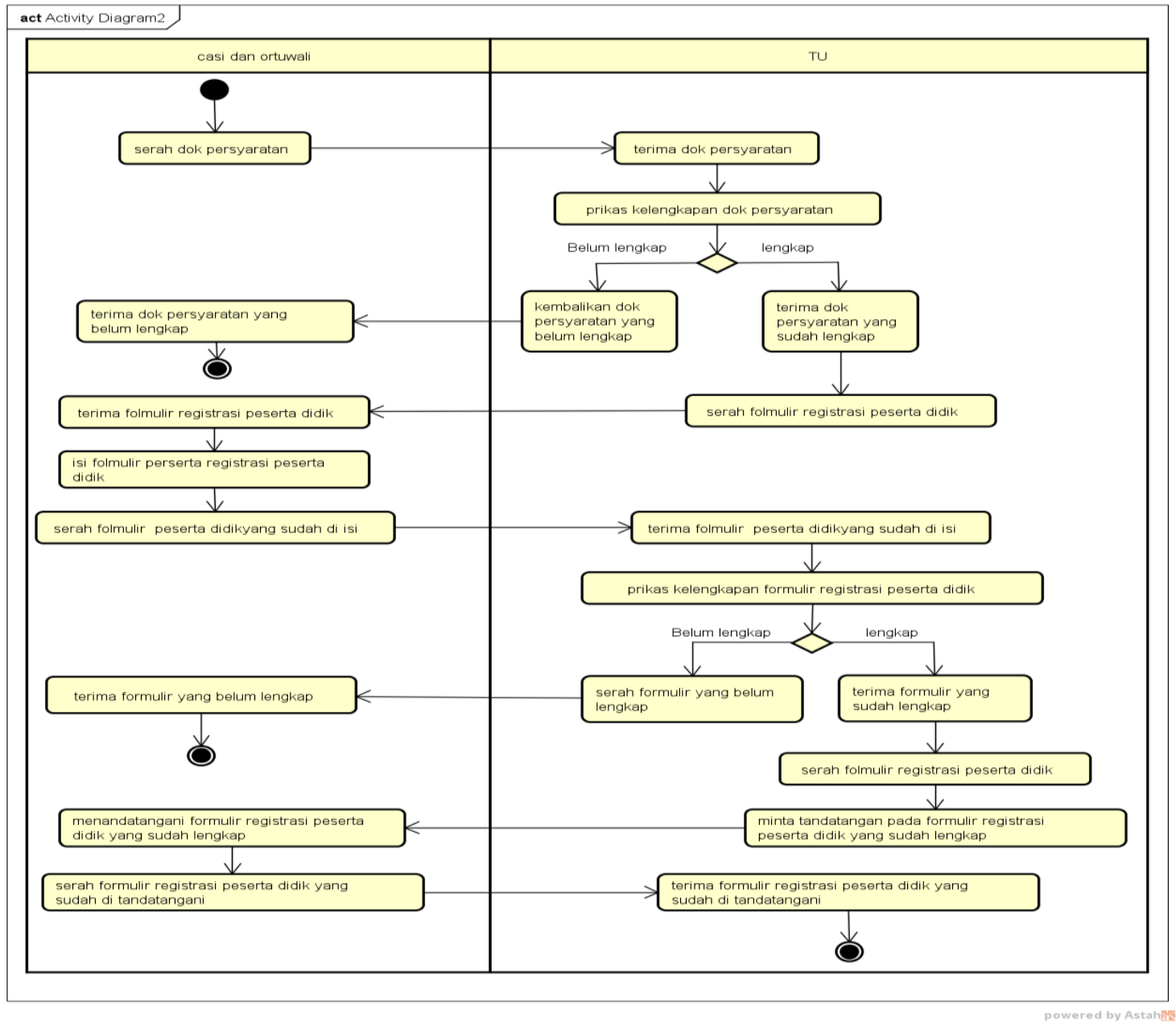

Gambar 4 Activity Diagram Registrasi Peserta Didik

\section{Activity Diagram Proses Pindah Sekolah}

Jika ada murid yang mau pindah sekolah, maka orang tua/wali murid meminta surat keterangan pindah sekolah ke bagian TU, TU akan memberikan format permintaan pindah sekolah kepada orang tua/wali. Setelah diisi, di cetak formulir pindah sekolah tadi, diserhakan ke TU nanti TU akan mengecek, apakah sudah benar atau belum. Kalau sudah benar nanti kepala sekolah akan menandatanganinya. Setealh ditanda tangani kepala sekolah, maka kepala sekolah akan menyerahkan kepada TU, pihak TU akan memberikan surat keterangan pindah ini kepada orang tua/wali murid. Proses ini bisa dilihat di gambar 5 . 


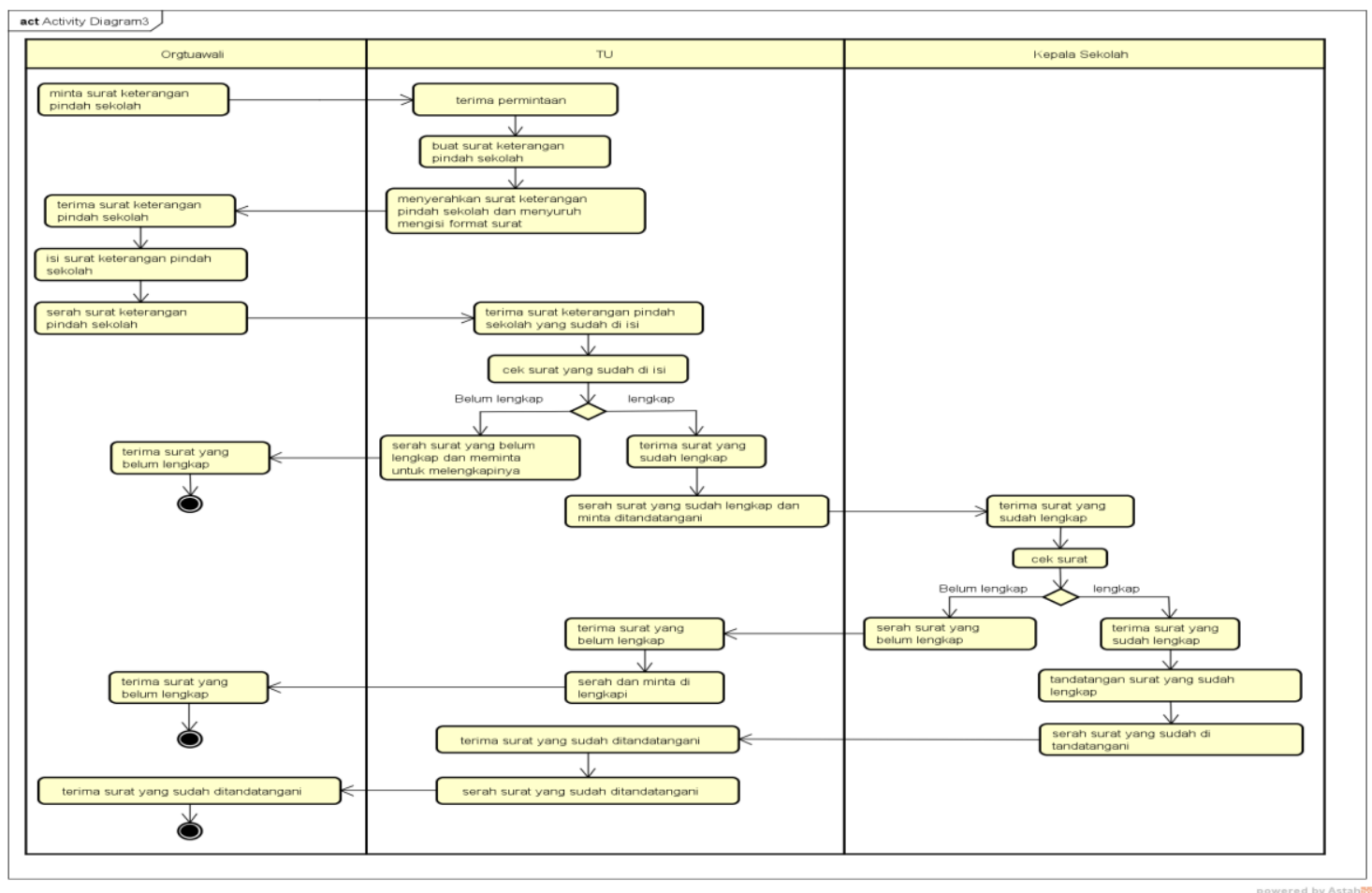

Gambar 5 Activity Diagram Proses Pindah Sekolah

B. Use Case Diagram, Use case diagram digunakan untuk menggambarkan interaksi antara sistem dengan para pemakai (user)

1. Use Case Diagram TU (Master)

Dalam Usecase ini actor yang ada hanyalah TU karena TU yang akan menginput beberapa data calon siswa yang akan mendaftar di SLBN Koba. Datadata yang diiput bias dilihat pada gambar dibawah ini yaitu gambar 6

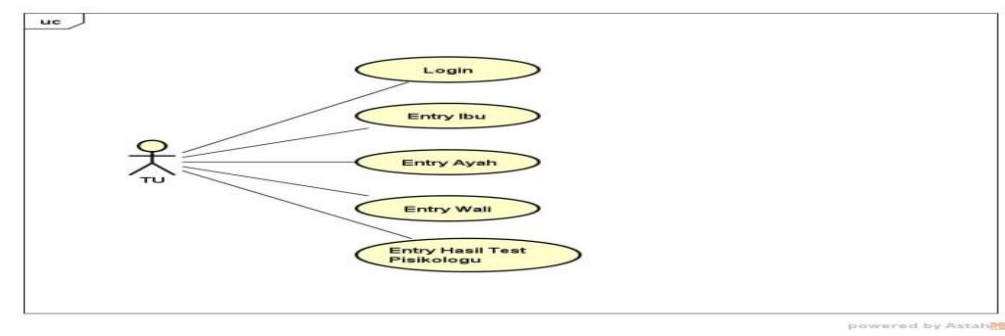

Gambar 6 Use Case Diagram TU (Master)

2. Use Case Diagram TU Transaksi

Semua Data transaksi pada proses PPDB yang ada pada SLBN KOba ini masih dilakukan oleh pihak TU. Proses proses ini ditunjukanpada gambar 7 di bawah ini

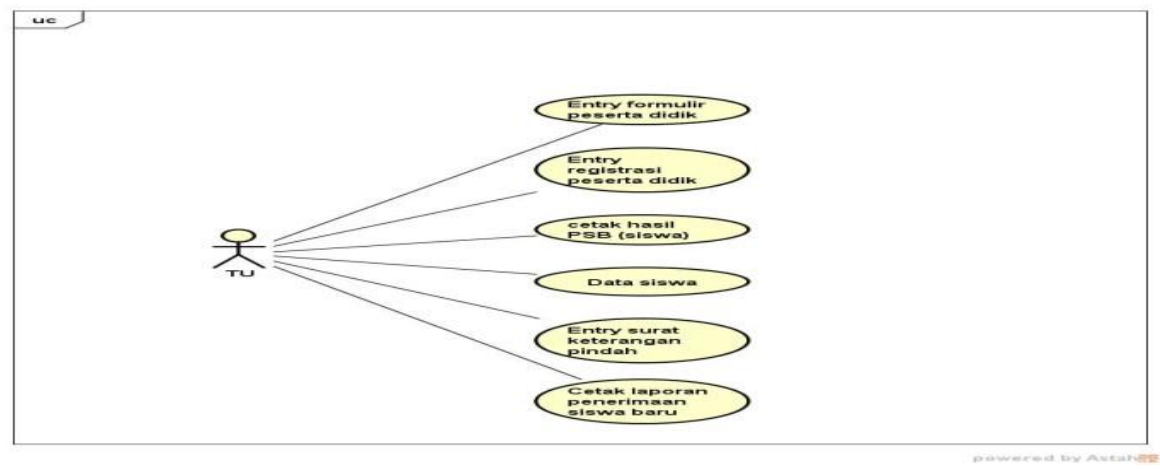


ISSN: 2503-054X

Jurnal Ilmu Komputer dan Teknologi Informasi Vol. 5 No: 2, Oktober 2020

Gambar 7 Use Case Diagram TU Transaksi

3. Use Case Diagram Orang Tua/Wali

Pada proses ini orang tualah yang menjadi actor, karena orang tua/wali menginput beberapa data yang diperlukan di dalam system PPDB pada SLBN Koba ini. Proses Pengentrian data-data yang dilakukan oleh orang tua bias dilihat pada usecase diagram orang tua/wali, di gambar 8

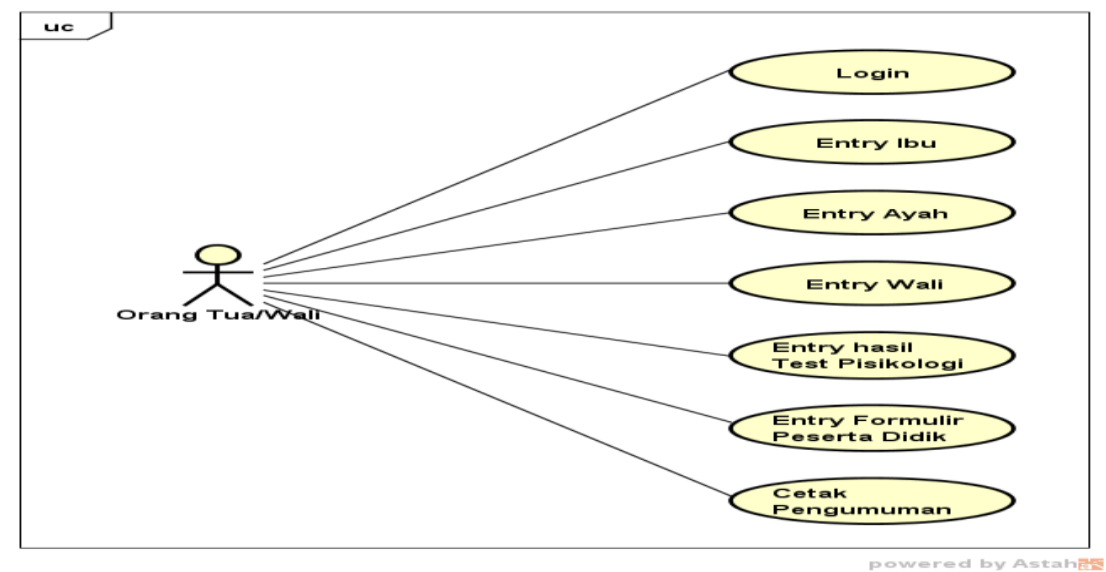

Gambar 8 Use Case Diagram Orang Tua/Wali

\section{Perancangan Basis Data}

1. Entity Relationship Diagram (ERD); Diagram ERD ini menggmabar tentang system yang ada dan system yang akan di buat oleh penulis. Didalam diagram ERD ada 7 Entitas yang menggambarkan proses yang terjadi. Adapun detail lengkap ERD ini bias dilihat pada gambar 9

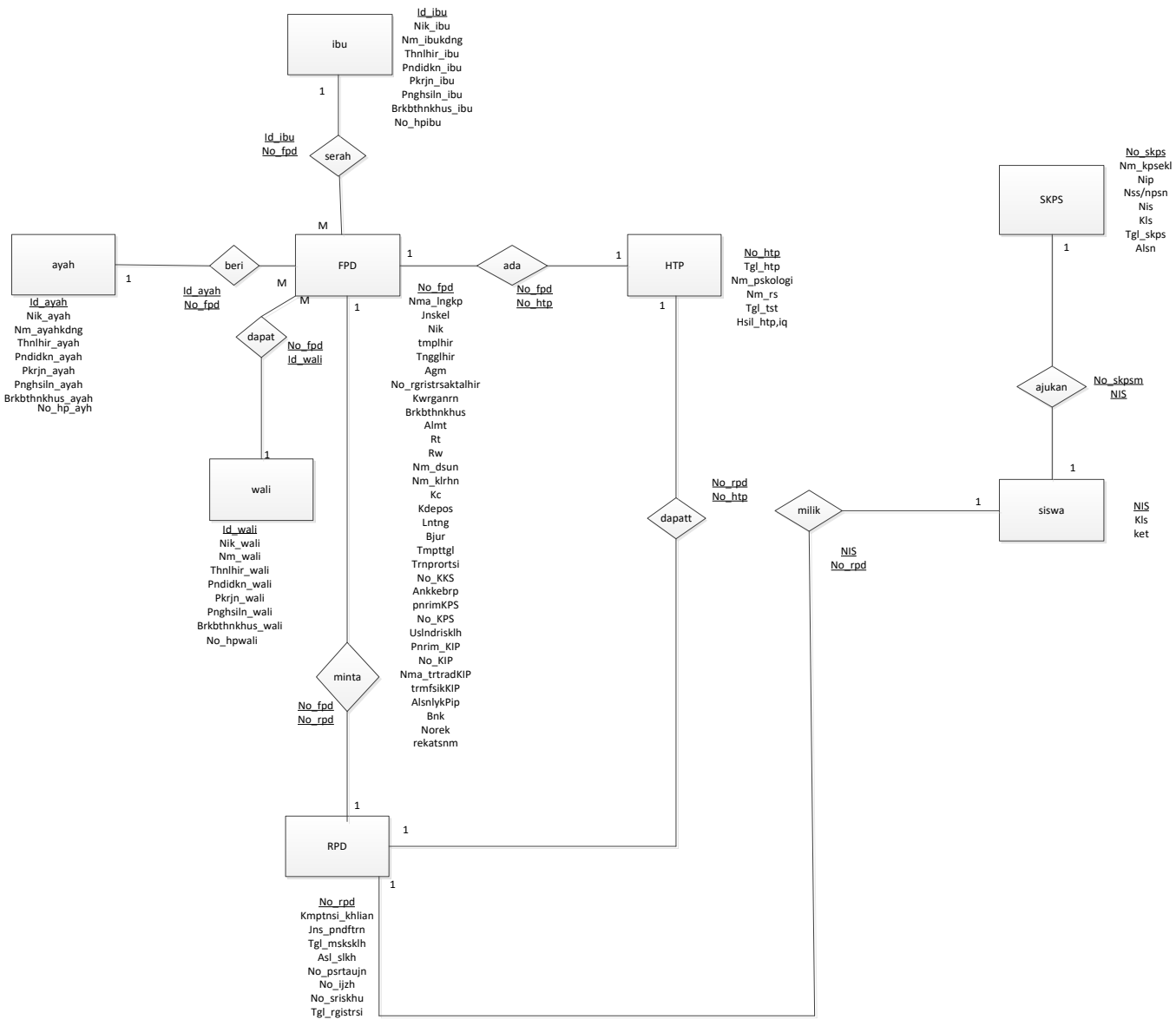


ISSN: 2503-054X

Jurnal Ilmu Komputer dan Teknologi Informasi

Vol. 5 No: 2, Oktober 2020

Gambar 9 Entity Relationship Diagram (ERD)

\section{2. $\quad$ Logical Record Structure (LRS)}

LRS terdiri dari link yang ada diLRS, link ini menunjukan arah dari satu tipe record lainnya. Banyak link dari LRS yang diberi tanda filed-field yang kelihatan pada kedua link type record. Detail LRS ini bias dilihat pada gambar 10

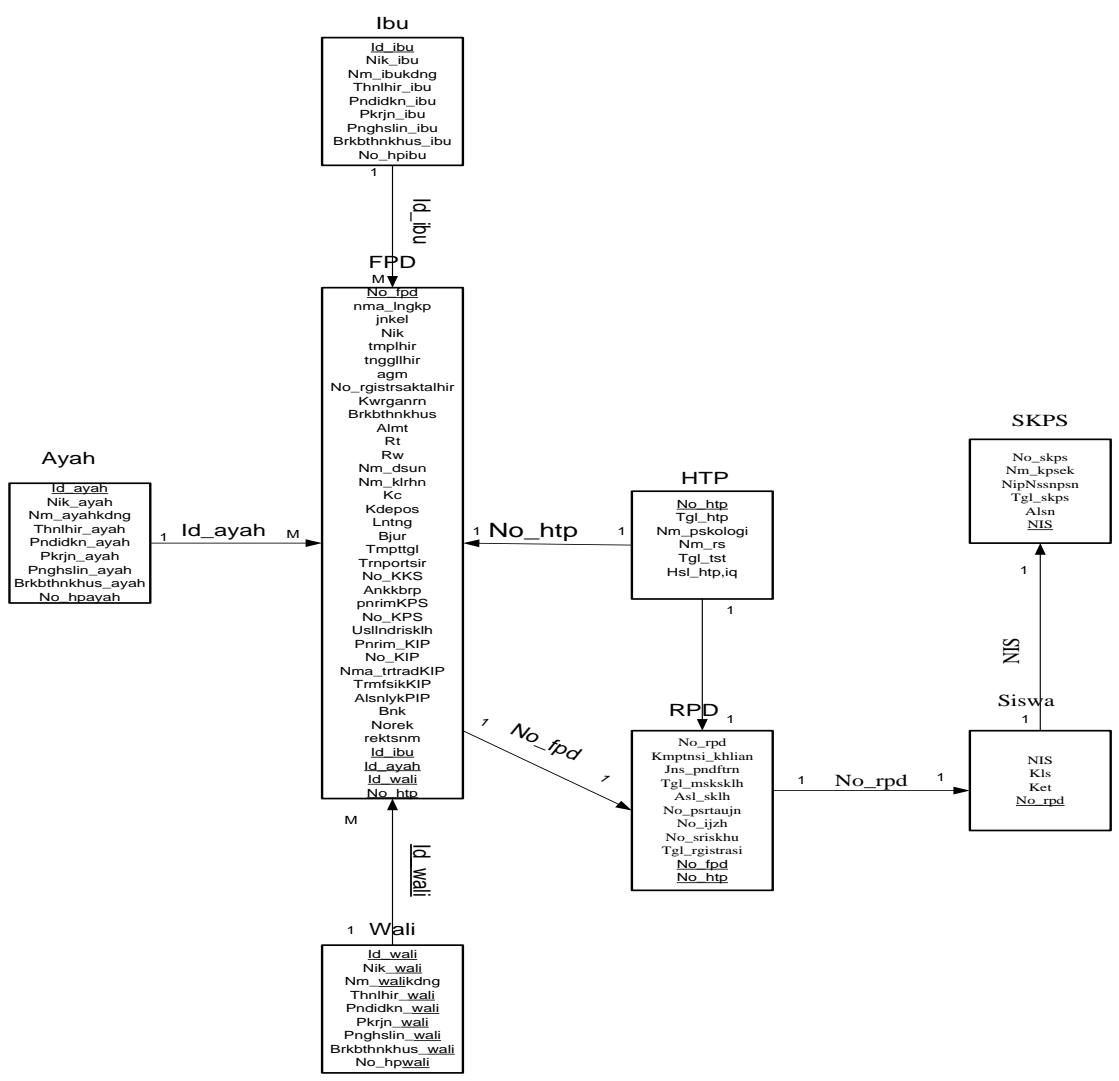

Gambar 10 Logical Record Structure

D. Rancangan Layar

Rancangan Layar merupakan tampilan interface yang akan digunakan user,dalam menginput atau melakukann transakdi dengan menggunakan system.

Dalam hal ini penulis membuat 7 tampilan layar terhadap PPDB di SLBN Koba

1. Rancangan Layar menu TU

Rancangan Layar Menu Utama adalah rancangan yang ada di awal tampilan pada system yang nantinya akan di gunakan. Tampilan layar ini bias dilihat pada gambar 11

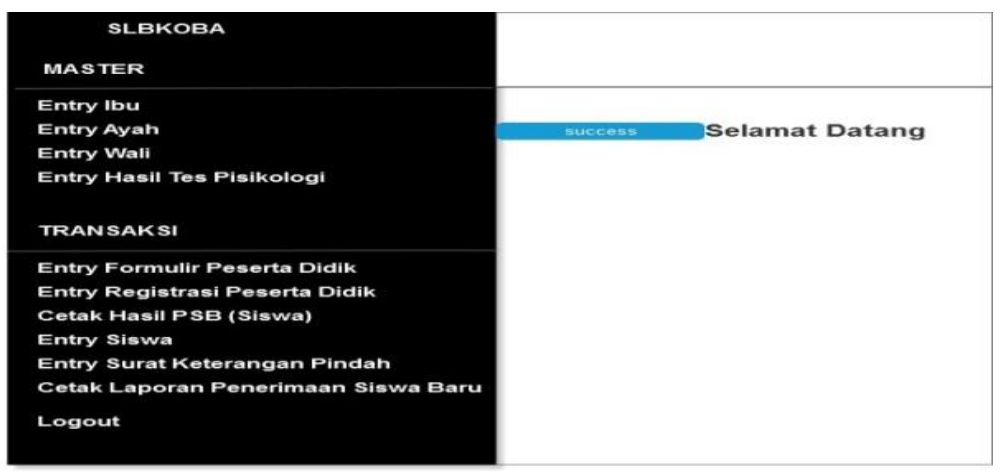


Gambar 11 Rancangan Layar menu TU

2. Rancangan Layar Hasil Test Psikologi

Rancangan layar ini di gunakan untuk memasukan data dari hasil psikologi. Test Psikologi yang dilakukan melibatkan instansi terkait yang ada. Proses input data hasil psikologi ini bias dilihat pada tampilan layar hasil psikologi di gambar 12

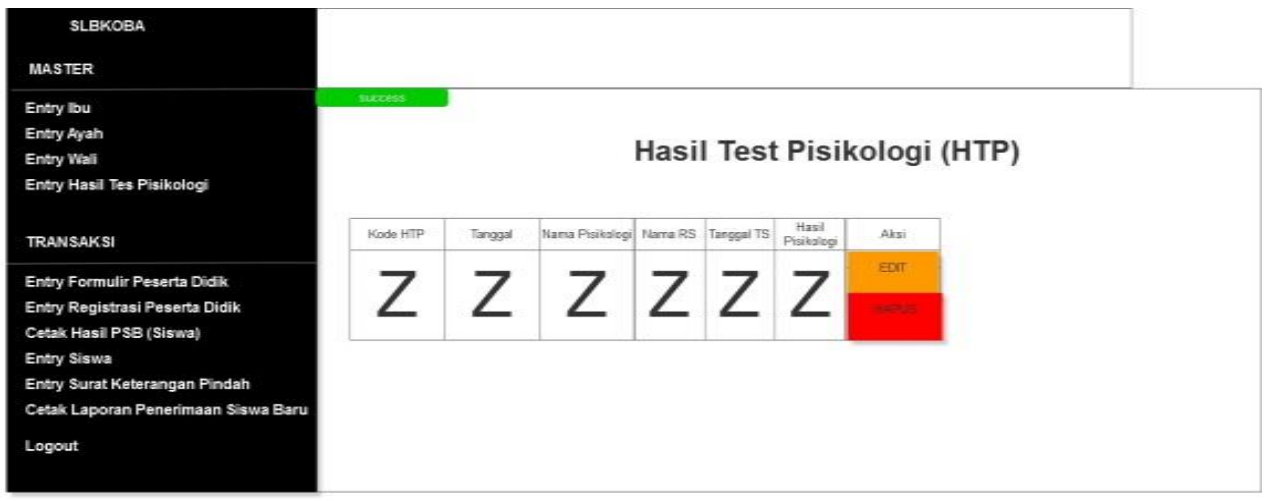

Gambar 12 Rancangan Layar Hasil Test Psikologi

3. Rancangan Layar Entry Formulir Peserta Didik

Adapun tampilan untuk pengisian formulir peserta didik bias dilihat pada gambar 13

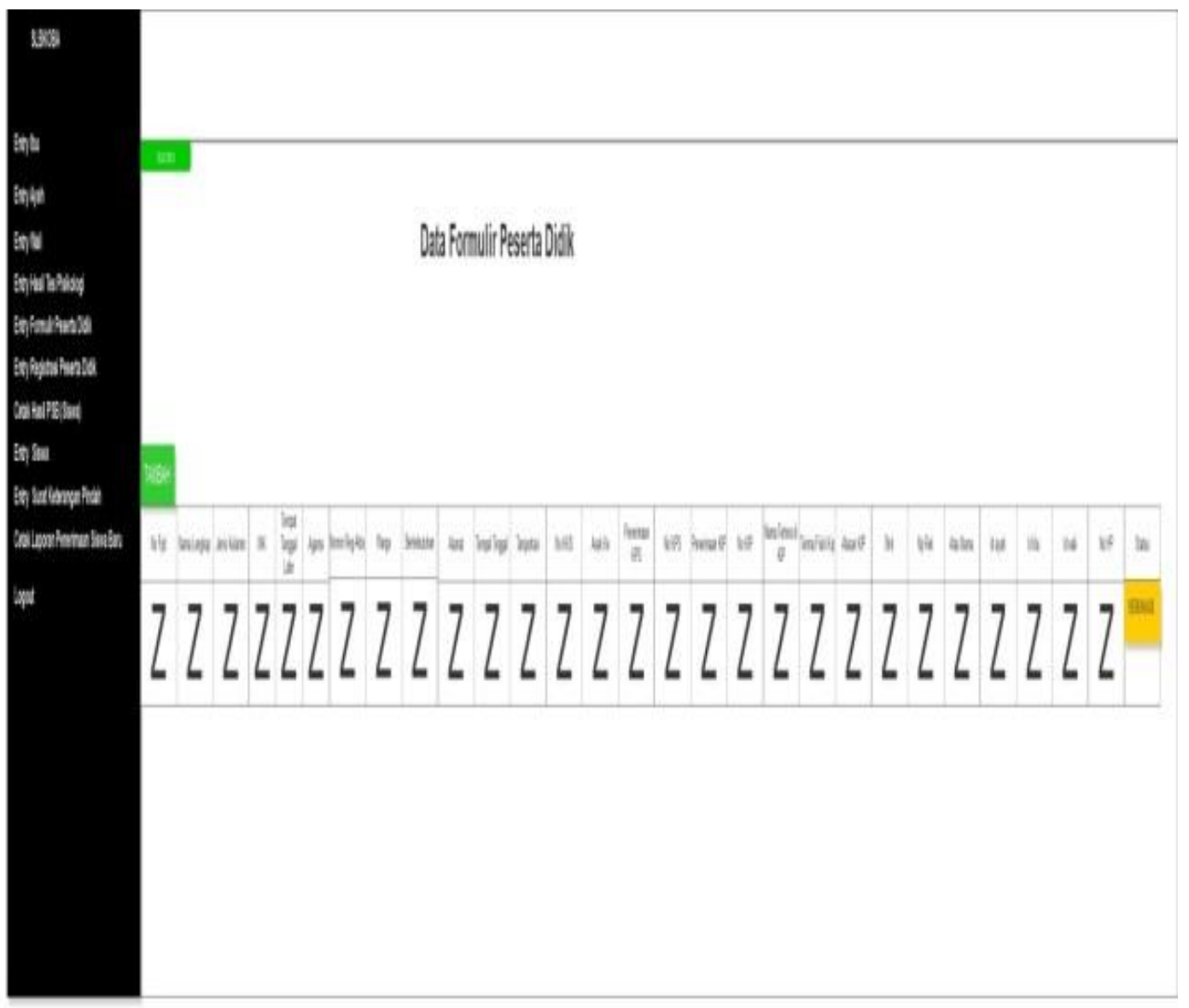

Gambar 13 Rancangan Layar Entry Formulir Peserta Didik

4. Rancangan Layar Menu Verifikasi 
Tampilan Menu Verifikasi di gunakan untuk melakukan verifikasi data terhadap calon siswa. Tampilan ini bias dilihat pada gambar 14

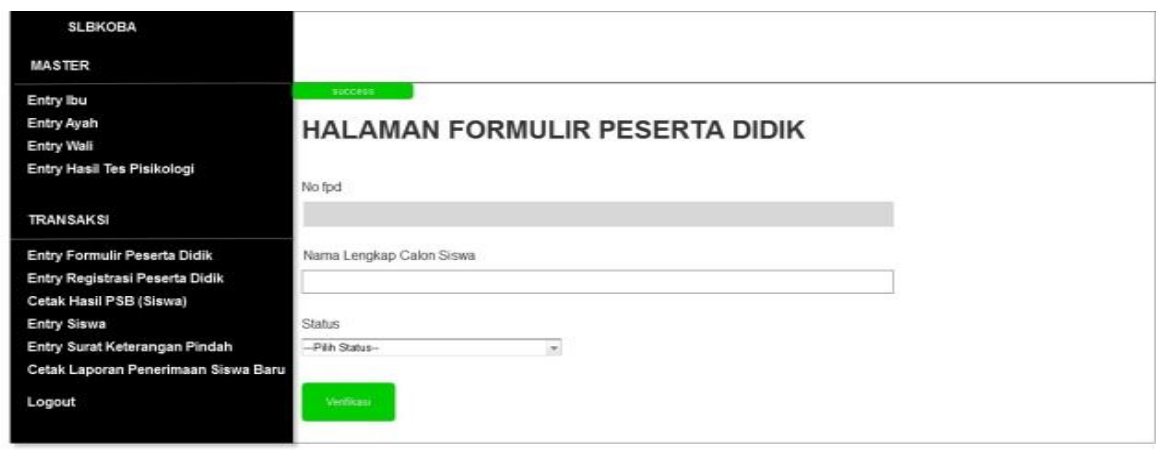

Gambar 14 Rancangan Layar Menu Verifikasi

5. Rancangan Layar Entry Registrasi Peserta Didik

Tampilan interface ini di buat agar peserta didik bias menginput data registrasi peserta didik (calon siswa), setelah melalui proses seleksi dan hasil dari psikologi. Tampilan layar ini bias di lihat pada gambar 15 di bawah ini

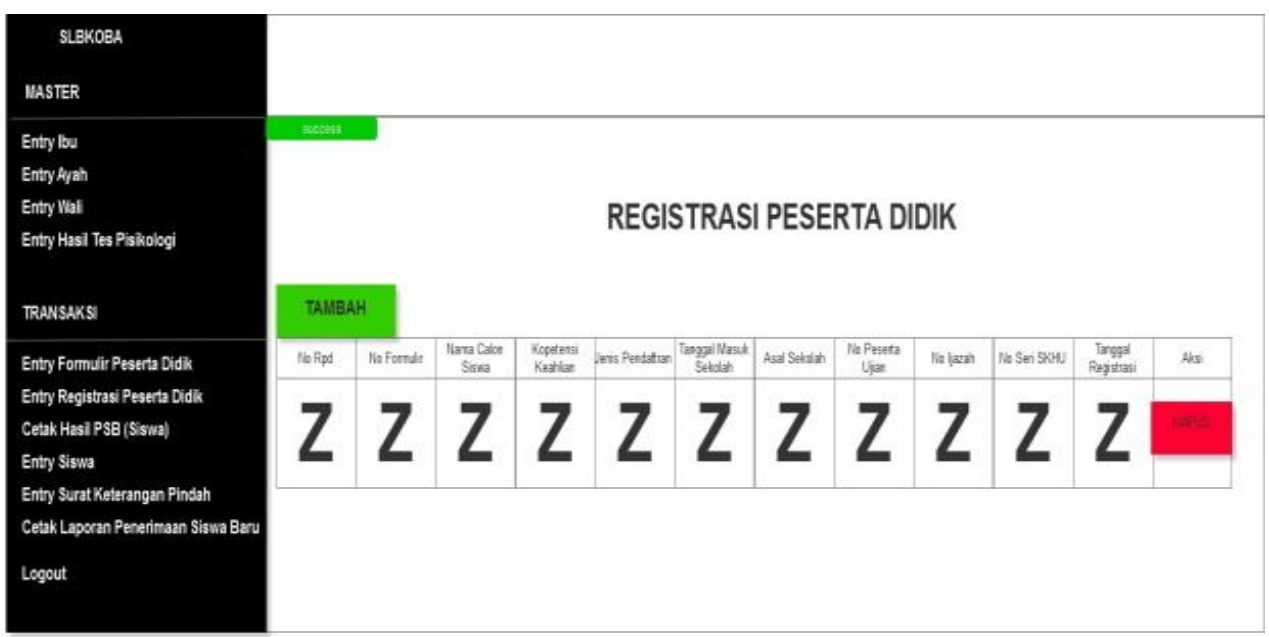

Gambar 15 Rancangan Layar Entry Registrasi Peserta Didik

6. Rancangan Layar Cetak hasil PPDB

Rancangan ini merupakan hasil dari semua data yang sudah di input ke dalam system. Gambar dari hasil ini bias dilihat pada gambar 16

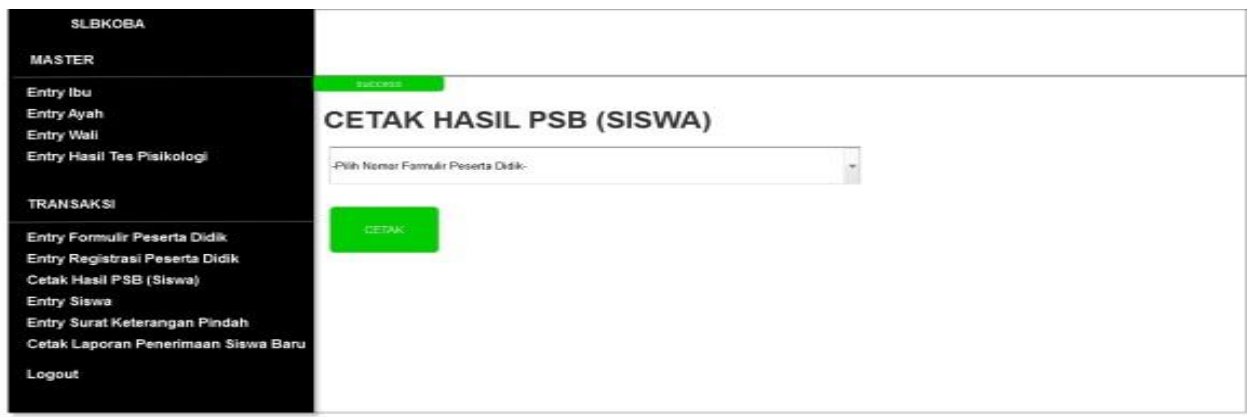

Gambar 16 Rancangan Layar Cetak hasil PSB (PPDB) 
7. Rancangan Layar Button Cetak

Tampilan ini merupakan hasil atau bukti dari cetakan PPDB terhadap calon siswa yang nantinya akan masuk di sekolah SLBN Koba. Gambar hasil cetakan ini bias diperlihatkan pada gambar 17

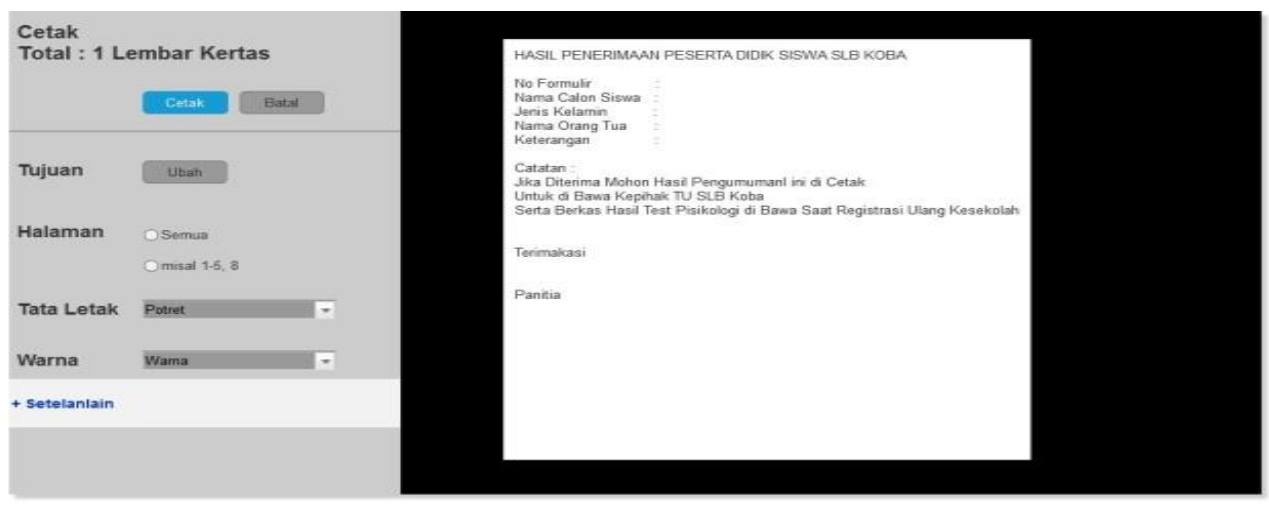

Gambar 17 Rancangan Layar Button Cetak

IV. Kesimpulan

Diperlunya pembuatan dan pemanfaatan sistem berbasis web terhadap PPDB (Penerimaan Peserta Didik Baru) Di SLBN Koba, agar memudahkan orang tua dan siswa yang akan mendaftar, baik kemudahan informasi pendaftarannya maupun pada saat pendaftaran sampai registrasi ulang. Selain itu dengan adanya sistem ini akan memudahkan pengolahan data lebih baik dan efektif serta bisa terintegrasi. Pastinya akan lebih Memudahkan pihak sekolah dalam pembuatan laporan PPDB dan kontrol terhadap pelaksanaan PPDB.

Agar sistem ini bisa digunakan maksimal oleh pihak sekolah dan masyrakat maka di perlukan adanya pelatihan kepada user dari sekolah dalam hal ini tata usaha usaha dan kepala sekolah agar bisa mengimplementasikan sistem ini dan mengelola data datanya.Adanya perawatan dan pemeliharaan software dan hardware untuk keberlangsungan sistem ini. Serta memerlukan jaringan internet yang baik agar sistem ini bisa di gunakan secara maksimal dan efisien dan efektif

\section{Daftar Pustaka}

[1] S. Sarwindah, "Sistem Pendaftaran Siswa Baru Pada SMP N 1 Kelapa Berbasis Web Menggunakan Model UML,” J. Sisfokom (Sistem Inf. dan Komputer), vol. 7, no. 2, p. 110, 2018, doi: 10.32736/sisfokom.v7i2.573.

[2] L. Setiyani, “[ Software Engineering ] Lila Setiyani, S . T , M . Kom,” no. May, pp. 20-25, 2019.

[3] M. Sukma, “済無No Title No Title,” 2015, doi: 10.1017/CBO9781107415324.004.

[4] K. \&Jane P. laudo. C.laudon, Management information systems: managing the digital firm, 8th Edition, vol. 24, no. 2. 2018.

[5] R. Witanto and H. Solihin, "PERANCANGAN SISTEM INFORMASI PENERIMAAN SISWA BARU BERBASIS WEB (STUDI KASUS : SMP PLUS BABUSSALAM BANDUNG),” vol. 1, pp. 54-63, Dec. 2016, doi: 10.5281/zenodo.1495820.

[6] N. A. Y. Ramadhani, "Pembangunan Sistem Informasi Penerimaan Siswa Baru Di Sekolah Menengah," J. Speed-Sentra Penelit. Eng. dan Edukasi, vol. 3, no. 3, pp. 35-43, 2011, [Online]. Available: https://s3.amazonaws.com/academia.edu.documents/32265940/664-1248-1SM.pdf?response-content-disposition=inline\%3B filename\%3DPEMBANGUNAN_SISTEM_INFORMASI_PENERIMAAN.pdf\&X-AmzAlgorithm=AWS4-HMAC-SHA256\&X-Amz-Credential=AKIAIWOWYYGZ2Y53UL3A\%2F20190802\%2Fus. 